\title{
Incorporating reef fish avoidance behavior improves accuracy of species distribution models
} \author{
Keith Kamikawa ${ }^{2}$, Euan S Harvey ${ }^{1}$ \\ ${ }^{1}$ Curtin University, Perth, Australia \\ 2 University of Hawai'i at Mānoa, Honolulu, United States \\ 3 NOAA Pacific Islands Fisheries Science Center, Honolulu, United States \\ 4 National Geographic Society, Washington DC, United States \\ Corresponding Author: Kostantinos A Stamoulis \\ Email address: kostanti@hawaii.edu
}

Kostantinos A Stamoulis ${ }^{\text {Corresp., } 1}$, Jade MS Delevaux ${ }^{2}$, Ivor D Williams ${ }^{3}$, Alan M Friedlander ${ }^{2,4}$, Jake Reichard ${ }^{2}$,

Species distribution models (SDMs) are used to interpret and map fish distributions based on habitat variables and other drivers. Reef fish avoidance behavior has been shown to vary in the presence of divers and is primarily driven by spearfishing pressure. Diver avoidance behavior or fish wariness may spatially influence counts and other descriptive measures of fish assemblages. Because fish assemblage metrics are response variables for SDMs, measures of fish wariness may be useful as predictors in SDMs of fishes targeted by spearfishing. We used a diver operated stereo-video system to conduct fish surveys and record minimum approach distance (MAD) of targeted reef fishes inside and outside of two marine reserves on the island of O'ahu in the main Hawaiian Islands. By comparing MAD between sites and management types we tested the assumption that it provides a proxy for fish wariness related to spearfishing pressure. We then compared the accuracy of SDMs which included MAD as a predictor with SDMs that did not. Individual measures of MAD differed between sites though not management types. When included as a predictor, MAD averaged at the transect level greatly improved the accuracy of SDMs of targeted fish biomass. 


\section{Incorporating reef fish avoidance behavior improves accuracy of species}

2 distribution models

3

4 Kostantinos A. Stamoulis ${ }^{1}$, Jade M.S. Delevaux ${ }^{2}$, Ivor D. Williams ${ }^{3}$, Alan M. Friedlander ${ }^{2,4}$, Jake

5 Reichard $^{2}$, Keith Kamikawa ${ }^{2}$, Euan S. Harvey ${ }^{1}$

6

${ }^{1}$ Curtin University, Perth, Australia.

${ }^{2}$ University of Hawai'i at Mānoa, Honolulu, United States.

${ }^{3}$ NOAA Pacific Islands Fisheries Science Center, Honolulu, United States.

${ }^{4}$ National Geographic Society, Washington DC, United States.

7

8 Corresponding author:

9 Kostantinos A. Stamoulis ${ }^{1}$

10

11 Email address: kostanti@hawaii.edu 


\section{Abstract}

13 Species distribution models (SDMs) are used to interpret and map fish distributions based on

14 habitat variables and other drivers. Reef fish avoidance behavior has been shown to vary in the presence of divers and is primarily driven by spearfishing pressure. Diver avoidance behavior or fish wariness may spatially influence counts and other descriptive measures of fish assemblages. Because fish assemblage metrics are response variables for SDMs, measures of fish wariness may be useful as predictors in SDMs of fishes targeted by spearfishing. We used a diver operated stereo-video system to conduct fish surveys and record minimum approach distance (MAD) of targeted reef fishes inside and outside of two marine reserves on the island of O'ahu in the main Hawaiian Islands. By comparing MAD between sites and management types we tested the assumption that it provides a proxy for fish wariness related to spearfishing pressure. We then compared the accuracy of SDMs which included MAD as a predictor with SDMs that did not. Individual measures of MAD differed between sites though not management types. When included as a predictor, MAD averaged at the transect level greatly improved the accuracy of SDMs of targeted fish biomass.

\section{Introduction}

A current focus in marine ecology has been to use species distribution models (SDMs) to understand and sometimes predict fish distributions based on habitat, environmental, and other drivers. Development of SDMs begins with observations of species distributions (typically summarized in terms of biomass, biodiversity, or similar metrics), and the identification and compilation of environmental variables known or believed to influence habitat suitability and, therefore, species distributions (Franklin 2010, Schmiing et al. 2013). Modeling approaches can be rule based or quantitative and can include statistical models, multivariate ordination, classification, machine learning, and Bayesian techniques (Norberg et al. 2019). SDMs are often applied for predictive mapping, producing spatial datasets and maps of species distributions and/or habitat suitability which, among other applications, can assist with marine spatial planning by identifying areas of high ecological significance. (Shucksmith and Kelly 2014, Stamoulis and

40 Delevaux 2015).

41 Fish species respond to their habitat in different ways depending on their life-history strategies, predators, competitors, and food availability (Sale 1998, Boström et al. 2011). Fishing pressure is a primary driver, not only of fish distributions (Jennings and Polunin 1996, Friedlander and DeMartini 2002), but also (in the case of spearfishing) of fish behavior (Kulbicki 1998). Fish behavior can be substantially altered by the presence of SCUBA divers, depending on fishes' prior experience of divers' activities (i.e. feeding vs spearing) (Cole 1994, Kulbicki 1998, Watson and Harvey 2007). Consequently, it is reasonable to expect that such variability in fish behavior would influence survey counts from underwater visual census conducted by observers on SCUBA (Brock 1954 ) - the most common survey method in shallow water coral reefs. Despite earlier recognition of the potential biases associated with variable responses of targeted fishes to divers (Kulbicki 1998), there have only been a few attempts to quantify the impacts of fishes' diver avoidance 
52 behavior on measures of fish assemblages (Dickens et al. 2011, Bozec et al. 2011). Because fish 53 assemblage metrics are response variables for SDMs, including measures of fish behavioral 54 responses to the presence of survey divers may improve the predictive power of SDMs for targeted 55 fishes.

Avoiding predators is a necessary and consistent behavior for reef fishes as well as most other animals (Lima and Dill 1990). One of the most common avoidance behaviors is fleeing which can incur energetic and opportunity costs (Ydenberg and Dill 1986). Human spear fishers are reef fish predators and targeted fishes avoid them in areas where spearfishing occurs, consistent with predation risk theory (Gotanda et al. 2009). Predator avoidance behavior diverts time and energy away from health and fitness enhancing activities such as foraging, parental care, and mating (Lima 1998, Frid and Dill 2002) and can also have consequences for ecosystem functions (Madin et al. 2010, Rizzari et al. 2014). The application of a predation risk framework may help to interpret the extent to which underwater survey counts reflect actual abundances vs a behavioral bias (Frid et al. 2019), the costs of avoidance behavior on body condition and reproduction (Spitz et al. 2019), and how these factors (together with fishery removals) may influence the results of SDMs. In locations with high spearfishing pressure, area-based fish survey methods may underestimate abundance of species targeted by spear fishers (Kulbicki 1998, Feary et al. 2010). Guam is a Pacific Island where SCUBA spearfishing has been practiced for over 30 years as part of the recreational and commercial reef-fish fisheries (Myers 1993, Houk et al. 2012). Lindfield et al. (2014) tested the magnitude of avoidance behavior and its influence on fish surveys in Guam using a diver operated stereo video system (stereo-DOV) to survey fish populations inside and outside of two no-take reserves and compared counts using standard open-circuit SCUBA and a closed-circuit rebreather. Closed-circuit rebreathers do not produce bubbles when operated at a constant depth and, therefore, greatly reduce the disturbance caused by survey divers' presence and the association with SCUBA spear fishers. The authors recorded 'minimum approach distance' (MAD): the distance between the diver and the fish at its closest point. In contrast to flight initiation distance, distance is recorded for every fish observed on a transect, even if the fish does not flee and moves away in what appears to be normal swimming activity (Lindfield et al. 2014). In addition, the observer moves at a steady pace along the transect and does not purposely approach fish with the goal of soliciting a flight response. Lindfield et al. (2014) found that fished sites sampled on open-circuit SCUBA had the greatest average MAD for targeted fish groups and abundance of targeted fishes was 2.6 times greater when surveyed on closed-circuit rebreather vs. open-circuit SCUBA in fished areas, whereas in reserves, counts were similar between diving modes. This demonstrates a dramatic impact of fish behavior on survey estimates due to avoidance of open-circuit SCUBA diver 'predators'. These effects were partially corroborated by Gray et al. (2016) who used a different underwater visual census method and found that biomass estimates of some targeted reef fishes were significantly lower on opencircuit SCUBA compared to closed-circuit rebreather at locations with high spearfishing pressure in the main Hawaiian Islands. 
91 Fishing has obvious and direct effects on targeted fish populations (Jackson et al. 2001). Patterns 92 of fishing pressure are difficult to measure and are rarely mapped (but see Stamoulis et al. 2018). 93 Diver avoidance behavior of targeted fishes may provide a proxy for spearfishing pressure 94 (Bergseth et al. 2015). Thus, inclusion of diver avoidance behavior in SDMs could have 95 explanatory power beyond correcting underwater survey bias. Spearfishing pressure directly 96 increases fish wariness and decreases true fish biomass, while increased fish wariness may further 97 decrease observed fish biomass, due to survey diver avoidance. Thus, including a measure of fish 98 wariness should improve explanatory power and predictive accuracy of SDMs. In order to test this 99 hypothesis, we used a stereo-DOV to (simultaneously) conduct belt-transects and record MAD of

100 targeted reef fishes both inside and outside of two marine reserves on the island of O'ahu in the 101 main Hawaiian Islands. We compare MAD between reserve and fished areas and between sites to 102 test the assumption that it provides a proxy for spearfishing pressure, then compare the accuracy 103 of SDMs including MAD as a predictor with SDMs that do not.

\section{Materials and Methods}

107 Surveys were conducted inside and outside of two no-take marine reserves on O'ahu in the 108 Hawaiian Islands (Fig. 1). Pūpūkea is located on the north shore of O'ahu and was originally 109 established in 1983. It was 10 ha when first established and allowed for a range of fishing 110 activities. In 2003 it was expanded to encompass 71 ha and fishing activities were prohibited.

111 Spearfishing effort in the adjacent fished area to the north was estimated to be $\sim 5,000 \mathrm{hrs} / \mathrm{yr} / \mathrm{km}^{2}$

112 (Delaney et al. 2017). Enforcement in this reserve is somewhat lacking and spearfishing has been

113 documented inside the boundaries, though large seasonal ocean swells ensure there is little

114 fishing during the winter months (Stamoulis and Friedlander 2013). Surveys of Pūpūkea were

115 conducted during June-October 2016. Hanauma Bay is located on the south-east corner of the

116 island and is the oldest MPA in the state, established in 1967. The entire bay is protected and

117 encompasses 41 ha of marine habitats. Spearfishing effort in the adjacent fished area - Maunalua

118 Bay - was estimated at $250 \mathrm{hrs} / \mathrm{yr} / \mathrm{km}^{2}$ (Delaney et al. 2017) and the habitat is compromised 119 due to urbanization and associated land-based impacts (Wolanski et al. 2009). The reserve is 120 continuously monitored, and compliance is very high. Hanauma Bay was surveyed between 121 February and May 2017. Both marine reserves are frequented by high numbers of recreational 122 scuba divers and snorkelers though fish feeding is prohibited. Transect locations at both sites 123 were randomly selected within management types (reserve and open) on hard-bottom habitats, 124 spaced a minimum distance of $80 \mathrm{~m}$ apart, using ArcGIS (Fig. 1).

125

126 Field surveys

127 Pre-determined survey locations were uploaded to GPS units for use in the field. Two divers 128 navigated to waypoints from shore or small boat and used a stereo-DOV to conduct a single $5 \mathrm{x}$ $12925 \mathrm{~m}$ belt transect on SCUBA (Fig. 2). Each transect began on the selected GPS point and 130 followed the depth contour. Transect length was measured using a $25 \mathrm{~m}$ line reel which was 
131 secured to the substrate at the beginning of the transect and rolled out as progress was made.

132 Survey time was standardized to three minutes per transect. Field surveys were conducted under

133 Hawai'i State special activity permit No. 2017-44.

134

135 Our stereo-DOV system used two Canon Legria HF G25 high-definition video cameras mounted

$1360.7 \mathrm{~m}$ apart on a base bar inwardly converged at $7^{\circ}$ to provide a standardized field of view. These

137 video cameras feature a 10x HD video lens with a 30.4-304mm (35mm equivalent) focal length.

138 Video was recorded at $1920 \times 1080$ (Full HD) resolution with a framerate of 25 frames/second.

139 The camera system was built by and purchased from https:/www.seagis.com.au. Stereo video

140 imagery was calibrated using the program CAL (SeaGIS), following the procedures outlined in

141 Harvey and Shortis (1998). This allowed for measurements of fish length, distance (range) and

142 angle of the fish from the center of the camera system, and standardization of the area surveyed

143 (Harvey et al. 2001, 2004).

144

145 The stereo-DOV system recorded imagery while the observer moved along the transect, from 146 which we measured the abundance, length, and MAD of all targeted reef fishes encountered on

147 the transect. The observer held the stereo-DOV pointing forward and parallel with the bottom

148 while swimming close to the substrate at a constant speed. Thus, each video-transect consisted of

149 three minutes of (stereo) video captured while the observer moved along each $25 \mathrm{~m}$ transect.

150 Fishes located greater than $10 \mathrm{~m}$ in front or $2.5 \mathrm{~m}$ to the left or right of the stereo-DOV system as

151 it was moved along the transect were excluded based on minimum visibility encountered and

152 transect dimensions (Fig. 2). Though visibility (water clarity) varied throughout the survey

153 period, for consistency we applied the $10 \mathrm{~m}$ distance threshold to all surveys. We selected

154 species targeted by spear fishers from the 'targeted' species classification of a recently published

155 study of fishing effects in the main Hawaiian Islands, which included species with $\geq 450 \mathrm{~kg}$ of

156 annual recreational or commercial harvest between 2000 and 2010, or that were otherwise

157 recognized as important for recreational, subsistence, or cultural fishing (Friedlander et al. 2018,

158 Table S1). Full approval for this research was provided by the Curtin University Animal Ethics

159 Committee in accordance with the Australian code for the care and use of animals for scientific

160 purposes (Approval number: AEC_2014_42).

161

162 Video analysis

163 Pairs of videos from the stereo-DOV system were analyzed using the program EventMeasure

164 (SeaGIS). The total length of each targeted reef fish encountered on the transect was measured

165 when the fish was closest to the stereo-DOV and computed by EventMeasure (Harvey et al.

166 2004). In the case of large schools, a representative subset of 6-10 individuals was measured, and

167 the remaining fishes in the school were allocated to those records based on size. Biomass was

168 calculated from length estimates using the length-mass conversion: $\mathrm{M}=a \mathrm{TL}^{b}$, where parameters

$169 a$ and $b$ are species-specific constants, TL is total length (cm), and M is mass (g). Length-mass

170 fitting parameters were obtained from a comprehensive assessment of length-weight fitting 
171 parameters for Hawaiian reef fish species (Froese and Pauly 2017). On transects where targeted

172 species were not recorded, biomass estimates were set to zero.

173

174 Fish wariness (MAD)

175 The shortest distance between the cameras and each targeted reef fish encountered on the

176 transect was identified during the length measurement procedure (see above) and the distance

177 was automatically computed by EventMeasure thus obtaining an accurate measurement of MAD

178 (Harvey et al. 2004). If this was not possible due to the angle of the fish or obstruction of the

179 camera view, another point was recorded and used to calculate MAD for the measured fish

180 (Lindfield et al. 2014).

181

182 Data analysis

183 Reserve effect

184 To test effectiveness of the marine reserves included in this study as well as differences between 185 sites, two-way ANOVAs were used to compare the effects of management (reserve vs fished)

186 and site - the two study locations that each include a no-take reserve and an adjacent control area

187 where spearfishing is permitted - on mean targeted fish biomass and body length by transect. To

188 meet test assumptions, mean targeted fish biomass was fourth root transformed and mean

189 targeted fish body length was $\ln (\mathrm{x})$ transformed to improve normality. Morans I was used to test

190 for spatial autocorrelation of mean biomass values between transects.

191

192 Fish wariness (MAD)

193 A generalized linear mixed model was used to compare patterns of MAD between sites and

194 management types and assess relationships with fish body length, angle of approach, and water

195 depth. While management and site were the primary variables of interest for this study, it was

196 necessary to include other variables which have been shown (or suspected) to influence fish

197 flight behavior in Hawai'i (Stamoulis et al. 2019). These variables along with the interaction

198 between management and site were included as fixed factors in the model, while transect number

199 and species were included as random factors. Transect number was included to account for

200 varying sample sizes by transect and species was included to account for species related

201 differences in flight behavior. A gamma distribution with a log link function was applied as it

202 was found to best fit the response variable distribution. Continuous variables were scaled prior to

203 modeling and parameters were estimated with the Laplace approximation. To ensure that results

204 of this model were not confounded by differences in targeted fish body length between sites and

205 management types, a separate (otherwise identical) model was used to test these interactions.

206

207 Species distribution models

208 SDMs were developed using $60 \times 60 \mathrm{~m}$ resolution grid and all inputs were standardized

209 accordingly. Survey variables were summarized at the transect level and these values were

210 attributed to the corresponding grid cell. Targeted reef fish biomass was summed, and MAD was 
211 averaged for each transect. Boosted regression trees were used to develop SDMs of the total

212 biomass of targeted reef fish for both study areas combined. SDMs and spatial predictions were

213 generated in R (R Core Team 2014) using the dismo (Hijmans et al. 2014) and raster (Hijmans

214 2014) packages. Boosted regression trees are effective at modeling nonlinearities, discontinuities

215 (threshold effects) and interactions between variables (Breiman 1996, 2001, De'ath and

216 Fabricius 2000). Targeted reef fish biomass was modeled using a Gaussian distribution and a

217 fourth root transformation was applied to improve normality.

218

219 Model fitting and selection was accomplished following the procedures detailed in Elith et al.

220 (2008). To increase parsimony, selected models were then simplified to remove less informative

221

222 predictor variables (Elith et al. 2008). Starting with the selected best model and full set of predictor variables, the predictor contributing the least was identified and dropped, the model

223 was re-fit, and the change in predictive deviance was calculated relative to the initial model. This

224

225

226 process determined how many predictors could be dropped without resulting in a reduction of predictive performance. Simplification generally resulted in models with $<10$ predictors. Models with a larger number of predictors generally have higher percent deviance explained. To allow

227 for comparison, the top eight predictors were retained for all models. Then, the model training dataset was repeatedly sampled with replacement to create 20 bootstrap samples. Using the optimal parameter value combination and simplified set of eight predictor variables, a boosted regression tree model was fitted to each bootstrap sample and used to make predictions based on the values of the predictor variables at each transect location. The mean of the bootstrapped predictions was used for interpretation and further analysis.

Habitat variables were those used in (Stamoulis et al. 2018) following a pairwise correlation analysis for the Main Hawaiian Islands and conversion to a $60 \times 60 \mathrm{~m}$ resolution grid. There were 23 total habitat variables of four broad categories: seafloor topography, benthic habitat composition, geographic, and wave energy (Table 1, see Table S2 for further details). Four transects in the open area near Hanauma Bay did not have remotely sensed habitat data and were excluded from SDMs.

To determine whether including behavior as a predictor improved model fit and predictive performance, models were developed separately using predictor sets that included and excluded MAD. In addition to the habitat variables described above, management type (reserve/open) was included as a predictor after testing its correlation with MAD. In summary, two boosted regression tree models were developed combining data from both sites to explain and predict targeted fish biomass; 1) habitat + management, and 2) habitat + management + MAD.

Model fit was evaluated using cross-validated percent deviance explained and cross-validated 250 standard error. Predictive performance was assessed by comparing predicted values to observed values for each location. Accuracy of predictions was measured using $\mathrm{R}^{2}$ and Gaussian rank 
251 correlation estimate (Boudt et al. 2012), as well as root mean square error and symmetric mean

252

253

254

255

256

257

258

259

260

261

262

263

264

265

266

267

268

269

270

271

272

273

274

275

276

277

278

279

280

281

282

283

284

285

286

287

288

289

290

absolute percent error, an alternate to mean absolute percent error that is robust to zero values.

\section{Results}

Sampling and reserve effect

Stereo-DOV belt transect surveys were conducted inside the marine reserves and in the adjacent open areas at both Pūpūkea and Hanauma Bay (Table 2). These resulted in a total of 1,486 observations of 35 coral reef fish species targeted by spear fishers in Hawai' $i$ (Table S1). Reserve locations had higher abundances of targeted species such that the majority of observations occurred at locations protected from fishing (Table 2). At Hanauma Bay, 25\% of transects had no targeted fishes and at Pūpūkea $13 \%$ of transects had no targeted fishes. With few exceptions, these transects were located in the fished areas at each study site. Both marine reserves had significantly higher biomass of targeted fishes $\left(\mathrm{F}_{1,120}=48.9, \mathrm{p}<0.001\right)$ compared to adjacent fished areas, though the magnitude differed. The ratio of mean targeted fish biomass inside the reserve vs. outside was 4.9 for Hanauma Bay and 1.5 for Pūpūkea. In contrast, there was no significant difference in mean targeted fish body length for both marine reserves compared to adjacent fished areas $\left(\mathrm{F}_{1,95}=1.0, \mathrm{p}>0.05\right)$. There was also no difference between sites for mean biomass $\left(\mathrm{F}_{1,120}=2.1, \mathrm{p}>0.05\right)$ or mean body length $\left(\mathrm{F}_{1,95}=3.2, \mathrm{p}>0.05\right)$. Morans I test for spatial autocorrelation indicated spatial independence of measured biomass values $(\mathrm{Z}=1.1$, $\mathrm{p}>0.05)$.

Fish wariness (MAD)

MAD ranged from 0.8-10 $\mathrm{m}$ and was not significantly different inside and outside of reserves, though differed between sites (Table 3). MAD at Pūpūkea was significantly higher overall compared to Hanauma Bay (Fig. 3). Fish length, depth, and angle of approach were all significantly positively related to MAD (Table 3, Fig. 3). Fish length ranged from 4-70 cm, transect depth ranged from $0.5-17 \mathrm{~m}$, and angle of approach ranged from 0-25 degrees. The model which included interaction terms of targeted fish body length with site and management type, respectively, showed no significant effect of either Fish length $x$ Site $(t=1.4, p>0.05)$ or Fish length $\mathrm{x}$ Mgmt $(\mathrm{t}=-1.9, \mathrm{p}>0.05)$.

\section{$\underline{\text { Species distribution models }}$}

Management type was not correlated with MAD (Spearman rho $=0.1$ ). The model that included management, but not behavior explained $31 \%$ of the variability in targeted fish biomass for Hanauma Bay and Pūpūkea combined (CV PDE, Table 4). For the model where MAD was included as a predictor, CV PDE increased by $38 \%$ (Table 4). For this model, MAD accounted for $71 \%$ of explained variation for both sites combined (Fig. 4) and prediction accuracy increased with larger values of $\mathrm{R}^{2}$ and GRCE compared to models which did not include MAD (Table 4). Prediction error for all three measures decreased when MAD was added to the model (Table 4) and MAD explained the greatest amount of variability compared to other predictors 
291 (Fig. 4). In the models including management status but not behavior, management was not

292 selected as a final predictor.

293

294

295

296

297

298

\section{Discussion}

Management and site differences in fish wariness

Measurements of MAD did not differ significantly by management type, though they did differ between sites, with larger values at the site with higher spearfishing pressure. These results are

299 consistent with the hypothesis that MAD is a proxy of fish wariness that increases with

300 spearfishing pressure and correspond to those of Lindfield et al. (2014) who compared the MAD

301 of targeted fishes between reserves and fished areas in Guam, and Goetze et al. (2017) who measured MAD of targeted species before and after harvest events in periodically harvested closures in Fiji. In the latter study, increases in fish wariness were evident across all size ranges of targeted species when fish drives - where villagers work together to drive fish into gillnets were used as a harvest method. In contrast, spearfishing primarily affected larger individuals (Goetze et al. 2017). Fish drives are rarely utilized in modern times in Hawai'i and not at the sites included in this study, so we assume spearfishing to be the primary cause of increased fish wariness to human divers and do not expect an influence from passive capture methods such as hook and line.

MAD was significantly higher on average at Pūpūkea on the north shore of O'ahu, compared to Hanauma Bay on the south shore. A likely explanation is that spearfishing pressure is also higher at Pūpūkea, both outside and inside the reserve. Januchowski-Hartley et al. (2015) showed that FID increased with fishing pressure in both fished areas and adjacent marine reserves in the Indo-Pacific, providing evidence of behavioral spillover. Surveys at Pūpūkea were conducted in the summer months when the wave conditions allow for diving/spearfishing and the shoreline at Pūpūkea is very accessible with multiple access points. Spear fishers can swim in from either boundary, or simply enter the reserve directly and illegal spearfishing has been documented (Stamoulis and Friedlander 2013). In contrast, shoreline access to the Hanauma Bay reserve is highly regulated and it is unlikely that any illegal spearfishing occurs, with the possible exception of divers crossing the seaward boundary from boats. Furthermore, spearfishing pressure in the area adjacent to the Hanauma Bay reserve is estimated to be only $5 \%$ of spearfishing pressure in the area adjacent to the Pūpükea reserve. Thus, low compliance at Pūpūkea reserve and low spearfishing pressure in the area adjacent to Hanauma Bay are likely responsible for the larger effect of site than management on MAD in this study. Likewise, low compliance at Pūpūkea likely contributes to the small relative difference in targeted fish biomass compared to Hanauma Bay where low biomass in the open area is presumably due to poor habitat as much as fishing.

Effects of other variables on fish wariness 
330 Fish body length had a positive relationship with MAD as shown in previous studies (Lindfield

331 et al. 2014, Goetze et al. 2017). Reproductive value often increases with size in fishes (Birkeland

332 and Dayton 2005), and theory predicts that risk-taking should decrease at higher levels of

333 reproductive value (Clark 1994). In addition, larger fishes are often preferentially targeted by

334 fishers and may have more experience with this threat, so are more willing to incur fleeing costs

335 compared to smaller fishes (Tsikliras and Polymeros 2014, Samia et al. 2019). Previous studies

336 using flight initiation distance (FID) as a measure of fish wariness also showed a positive

337 relationship with body length (Gotanda et al. 2009, Januchowski-Hartley et al. 2011, 2015,

338 Bergseth et al. 2016). The strong positive relationship between fish body length and MAD could

339 lead to concerns that modeled differences in MAD between sites and management types may be

340 confounded. While including fish body length as a fixed factor in the generalized linear mixed

341 model should have accounted for body length effects, a separate model showing no significant

342 effects of the interactions between fish body length with site and management confirmed that

343 modeled differences were based on MAD and not fish body length. In addition, comparisons of

344 mean targeted fish body length by transect showed no differences between sites or management

345 types.

346

347

348

349

350

351

352

353

354

355

356

357

358

359

360

361

362

363

364

365

Approach angle ranged from $0-25^{\circ}$ and had a significant positive relationship with MAD. Fishes

measured at a more oblique (higher) angle are farther from the transect and are consequently less likely to be approached closely compared to fishes nearer to the transect. In addition, the predation risk framework predicts a greater FID when approaches are more direct because a direct approach may indicate detection and intent to capture (Frid and Dill 2002). It follows that MAD is also influenced by approach angle in this way since they are both measures of fish wariness. In contrast to our results, Goetze et al. (2017) did not find a relationship between MAD and approach angle.

Depth had a positive relationship with MAD. This is contrary to previous findings which showed depth to have a negative relationship with FID (Stamoulis et al. 2019). This effect is likely context dependent, and the positive influence of depth in this study reflects the low MAD in shallow areas of the marine reserves surveyed in this study. Both Hanauma Bay and Pūpūkea receive a large number of visitors who come to enjoy the abundant marine life. The majority of tourists tend to remain in shallow areas, thus targeted fishes in these marine reserves are likely habituated to non-aggressive human interactions, leading to reduced MAD in shallow areas. In contrast, the marine reserve surveyed by Stamoulis et al. (2019) has restricted access and does not receive many visitors. These findings suggest that fish flight behavior can be mediated by human interactions even in the absence of spearfishing (Titus et al. 2015).

366

367

MAD as predictor for species distribution models

368 Including MAD as a predictor for SDMs greatly improved model fits and predictive

369 performance. Despite some outliers at the low end of the scale, the partial dependence plot 
370 indicated an overall negative relationship between MAD and targeted fish biomass. In contrast, 371 management type was not selected as a final predictor for either model. Though we showed a 372 significant effect of management on targeted fish biomass, this suggests that habitat variation 373 within management types is an important driver. Likewise, mean MAD explains variation among

374

375

376

377

378

379

380

381

382

383

384

385

386

387

388

389

390

391

392

393

394

395

396

397

398

399

400

401

402

403

404

405

406

407

408

409 individual transects $(\mathrm{N}=120)$ while management status explains variation only between management types $(\mathrm{N}=2)$. We know that compliance differs between marine reserves in this study, so a dichotomous management status designation may be somewhat misleading. MAD was greater at the site with higher spearfishing pressure and had a negative relationship with targeted fish biomass when included in SDMs. Based on these results, mean MAD of targeted species at the transect level appears to be a robust measure of fish wariness when used in SDMs of targeted fish biomass.

The predation risk framework indicates that lower targeted fish biomass in fished areas may be due to the combined effect of fishery removals and the costs of antipredator behavior, in addition to potential survey bias due to avoidance behavior. Antipredator behaviors have the benefit of increasing survival in the face of predation risk, and the cost of diverting time and energy from foraging or other fitness enhancing activities (Lima and Dill 1990, Clark 1994). Our results indicate that MAD provides a measure of avoidance behavior that increases with perceived risk (spearfishing pressure), consistent with the economics of flight distance (Ydenberg and Dill 1986). With additional data and species-specific analyses, application of the predation risk framework may help to generate bias correction factors accounting for fish behaviors that can be related to individual and species characteristics that influence investment in antipredator behavior (Frid et al. 2019). For use in SDMs, it appears that including MAD as a predictor helps to account for behavioral survey bias and improve model accuracy and predictive performance.

It is unclear what portion of the variance explained by MAD in SDMs was due to survey bias from fish behavior and what portion was due to the direct effects of spearfishing pressure, for which MAD provides a proxy. However, because the direction of these influences on observed targeted fish biomass are the same (negative), it is irrelevant to SDM performance. In order to validate the use of MAD as a proxy for spearfishing, future research should focus on comparing empirical measures of spearfishing pressure with MAD of targeted species to better quantify this relationship. A drawback of using MAD as a predictor for SDMs is that it is not possible to make predictions to locations for which MAD data is not available. Instead, spatially explicit estimates of spearfishing pressure could be used directly as a predictor for SDMs (e.g., Stamoulis et al. 2018). A better understanding of the relationship of MAD and spearfishing pressure would help inform this work so that MAD could be used to ground-truth spatial models of fishing pressure.

Another possibility is integrating MAD directly into measures of fish assemblage characteristics used to calibrate SDMs. Distance-based sampling, which is widely used for terrestrial mammals and birds but less so for coral reef fishes (though see Kulbicki 1998, Kulbicki et al. 2010), is one 
410 approach that may allow incorporation of MAD. Specifically, in distance sampling, observers 411 record the distance of each organism of interest from the observer at the time of observation, 412 thereby incorporating an indirect measure of behavior (Buckland et al. 2005, Thomas et al. 413 2006). Creating a detection function, representing the probability of detection as a function of 414 distance from the line, allows for estimation of the proportion of fish missed within the surveyed 415 area, resulting in corrected density estimates (Buckland et al. 2005, Thomas et al. 2006). In this 416 case, detection functions could be generated using data from locations with no spearfishing 417 pressure, which should correct for altered fish behavior when applied in areas where spearfishing 418 occurs, thus generating more accurate density estimates for use in SDMs.

419

420

421

422

423

424

425

426

427

428

429

430

431

432

433

434

435

436

437

438

439

440

441

442

443

444

445

446

447

Alternatively, the use of miniature remotely operated vehicles (mini-ROVs) to sample fish populations may address many of the effects of diver avoidance behavior. While mini-ROVs will still move and create a visual stimulus that may create trade-offs similar to those associated with predation risk (Frid and Dill 2002), they do not produce bubbles and are $<1 \mathrm{~m}$ in length, (Sward et al. 2019), thereby removing the threat and much of the disturbance stimuli associated with human divers. Mini-ROVs can be outfitted with stereo-video systems for fish surveys and measurement of MAD (eg. Schramm et al. 2020). Raolt et al. (2020) compared underwater visual census results from mini-ROVs and human snorkelers and found that mini-ROV surveys detected greater abundance and diversity of fishes. Further research should compare stereo-video fish surveys conducted by mini-ROV to those conducted by human divers, such as in this study. MAD in particular should be compared to determine differences in fish flight behavior between methods and ascertain to what extent mini-ROVs can reduce survey bias associated with human divers and produce more accurate data for use in SDMs and other applications.

\section{Conclusions}

In this study, we tested whether using a measure of targeted fish wariness (MAD) as a predictor of targeted fish biomass in SDMs spanning marine reserve boundaries, improved explanatory power and predictive accuracy. Our results show that including mean MAD as a predictor in SDMs greatly improves model performance and accuracy compared to models using reserve status only. Diver operated stereo-video systems allow for efficient sampling of reef-fish assemblages as well as fish behavior and do not require extensive training, making them useful monitoring tools for managers and communities. Based on the results from this and two previous studies (Lindfield et al. 2014, Goetze et al. 2017), MAD appears to be a useful proxy for spearfishing pressure. In order to fully validate MAD as a proxy for spearfishing, future research should focus on comparing empirical measures of spearfishing effort with MAD of targeted species. In addition, research should seek to improve spatially explicit estimates of spearfishing pressure, for which MAD could provide a valuable reference, to extend SDM predictions to unsampled areas.

448

449

\section{Acknowledgements}


450 Thanks to Kathy Geweke (HI Division of Aquatic Resources) for facilitating the state permitting 451 process and to Kaipo Perez (Hanauma Bay) for his help and coordination. We would like to 452 thank those that assisted with fieldwork, Andrew Purves, Jonatha Giddens, Whitney Goodell, 453 Jackie Troller, and Ignacio Petit. We'd also like to thank Dr. Mark Hixon for sharing his 454 mooring in Hanauma Bay and Kara Miller for lending the use of her kayak to survey the shallow 455 sites in Maunalua Bay.

456 


\section{References}

458 Bergseth, B. J., G. R. Russ, and J. E. Cinner. 2015. Measuring and monitoring compliance in notake marine reserves. Fish and Fisheries 16:240-258.

460

461

462

463

464

465

466

467

468

469

470

471

472

473

474

475

476

477

478

479

480

481

482

483

484

485

486

487

488

489

490

491

492

493

494

495

496

Bergseth, B. J., D. H. Williamson, A. J. Frisch, and G. R. Russ. 2016. Protected areas preserve natural behaviour of a targeted fish species on coral reefs. Biological Conservation 198:202-209.

Birkeland, C., and P. K. Dayton. 2005. The importance in fishery management of leaving the big ones. Trends in Ecology \& Evolution 20:356-358.

Boström, C., S. Pittman, C. Simenstad, and R. Kneib. 2011. Seascape ecology of coastal biogenic habitats: advances, gaps, and challenges. Marine Ecology Progress Series 427:191-217.

Boudt, K., J. Cornelissen, and C. Croux. 2012. The Gaussian rank correlation estimator: robustness properties. Statistics and Computing 22:471-483.

Bozec, Y.-M., M. Kulbicki, F. Laloë, G. Mou-Tham, and D. Gascuel. 2011. Factors affecting the detection distances of reef fish: implications for visual counts. Marine Biology 158:969981.

Breiman, L. 1996. Bagging predictors. Machine Learning 24:123-140.

Breiman, L. 2001. Statistical modeling: The two cultures (with comments and a rejoinder by the author). Statistical Science 16:199-231.

Brock, V. E. 1954. A preliminary report on a method of estimating reef fish populations. The Journal of Wildlife Management 18:297-308.

Buckland, S. T., D. R. Anderson, K. P. Burnham, and J. L. Laake. 2005. Distance sampling. Page Encyclopedia of Biostatistics. John Wiley \& Sons, Ltd.

Clark, C. W. 1994. Antipredator behavior and the asset-protection principle. Behavioral Ecology 5:159-170.

Cole, R. G. 1994. Abundance, size structure, and diver-oriented behaviour of three large benthic carnivorous fishes in a marine reserve in Northeastern New Zealand. Biological Conservation 70:93-99.

De'ath, G., and K. E. Fabricius. 2000. Classification and regression trees: a powerful yet simple technique for ecological data analysis. Ecology 81:3178-3192.

Delaney, D. G., L. T. Teneva, K. A. Stamoulis, J. L. Giddens, H. Koike, T. Ogawa, A. M. Friedlander, and J. N. Kittinger. 2017. Patterns in artisanal coral reef fisheries revealed through local monitoring efforts. PeerJ 5:e4089.

Dickens, L. C., C. H. R. Goatley, J. K. Tanner, and D. R. Bellwood. 2011. Quantifying relative diver effects in underwater visual censuses. PLoS ONE 6:e18965.

Elith, J., J. R. Leathwick, and T. Hastie. 2008. A working guide to boosted regression trees. Journal of Animal Ecology 77:802-813.

Feary, D. A., J. E. Cinner, N. a. J. Graham, and F. A. Januchowski-Hartley. 2010. Effects of customary marine closures on fish behavior, spear-fishing success, and underwater visual surveys. Conservation Biology 25:341-349.

PeerJ reviewing PDF | (2019:04:37092:2:0:NEW 27 Apr 2020) 
497 Franklin, J. 2010. Mapping species distributions: spatial inference and prediction. Cambridge $498 \quad$ University Press.

499 Frid, A., and L. Dill. 2002. Human-caused disturbance stimuli as a form of predation risk.

$500 \quad$ Conservation Ecology 6:11.

501 Frid, A., M. McGreer, and T. Frid. 2019. Chasing the light: Positive bias in camera-based

502 surveys of groundfish examined as risk-foraging trade-offs. Biological conservation $503 \quad 231: 133-138$.

504 Friedlander, A. M., and E. E. DeMartini. 2002. Contrasts in density, size, and biomass of reef 505 fishes between the northwestern and the main Hawaiian islands: the effects of fishing 506 down apex predators. Marine Ecology Progress Series 230:253-264.

507

508

509

510

511

512

513

514

515

516

517

518

519

520

521

522

523

524

525

526

527

528

529

530

531

532

533

534

535

536

Friedlander, A. M., M. K. Donovan, K. A. Stamoulis, I. D. Williams, E. K. Brown, E. J. Conklin, E. E. DeMartini, K. S. Rodgers, R. T. Sparks, and W. J. Walsh. 2018. Human-induced gradients of reef fish declines in the Hawaiian Archipelago viewed through the lens of traditional management boundaries. Aquatic Conservation: Marine and Freshwater Ecosystems 28:146-157.

Froese, R., and D. Pauly. 2017. FishBase. Online database. www.fishbase.org.

Goetze, J. S., F. A. Januchowski-Hartley, J. Claudet, T. J. Langlois, S. K. Wilson, and S. D. Jupiter. 2017. Fish wariness is a more sensitive indicator to changes in fishing pressure than abundance, length or biomass. Ecological Applications 27:1178-1189.

Gotanda, K. M., K. Turgeon, and D. L. Kramer. 2009. Body size and reserve protection affect flight initiation distance in parrotfishes. Behavioral Ecology and Sociobiology 63:15631572.

Gray, A. E., I. D. Williams, K. A. Stamoulis, R. C. Boland, K. C. Lino, B. B. Hauk, J. C. Leonard, J. J. Rooney, J. M. Asher, K. H. L. Jr, and R. K. Kosaki. 2016. Comparison of reef fish survey data gathered by open and closed circuit SCUBA divers reveals differences in areas with higher fishing pressure. PLOS ONE 11:e0167724.

Harvey, E., D. Fletcher, and M. Shortis. 2001. A comparison of the precision and accuracy of estimates of reef-fish lengths determined visually by divers with estimates produced by a stereo-video system. Fishery Bulletin 99:63-71.

Harvey, E., D. Fletcher, M. R. Shortis, and G. A. Kendrick. 2004. A comparison of underwater visual distance estimates made by scuba divers and a stereo-video system: implications for underwater visual census of reef fish abundance. Marine and freshwater research 55:573-580.

Harvey, E. S., and M. R. Shortis. 1998. Calibration stability of an underwater stereo-video system: Implications for measurement accuracy and precision. Marine Technology Society Journal 32:3-17.

Hijmans, R. J. 2014. Raster: Geographic data analysis and modeling. http://CRAN.Rproject.org/package=raster.

Hijmans, R. J., S. Phillips, J. Leathwick, and J. Elith. 2014. dismo: Species distribution modeling. http://CRAN.R-project.org/package $=$ dismo. 
537 Houk, P., K. Rhodes, J. Cuetos-Bueno, S. Lindfield, V. Fread, and J. L. McIlwain. 2012.

538

539

540

541

542

543

544

545

546

547

548

549

550

551

552

553

554

555

556

557

558

559

560

561

562

563

564

565

566

567

568

569

570

571

572

573

574

575

Commercial coral-reef fisheries across Micronesia: a need for improving management. Coral reefs 31:13-26.

Jackson, J. B. C., M. X. Kirby, W. H. Berger, K. A. Bjorndal, L. W. Botsford, B. J. Bourque, R. H. Bradbury, R. Cooke, J. Erlandson, J. A. Estes, T. P. Hughes, S. Kidwell, C. B. Lange, H. S. Lenihan, J. M. Pandolfi, C. H. Peterson, R. S. Steneck, M. J. Tegner, and R. R. Warner. 2001. Historical overfishing and the recent collapse of coastal ecosystems. Science 293:629-637.

Januchowski-Hartley, F. A., N. A. J. Graham, J. E. Cinner, and G. R. Russ. 2015. Local fishing influences coral reef fish behavior inside protected areas of the Indo-Pacific. Biological Conservation 182:8-12.

Januchowski-Hartley, F., J. Cinner, N. Graham, T. Morove, and D. Feary. 2011. Fear of fishers: Human predation explains behavioral changes in coral reef fishes. PLoS One 6:e22761.

Jennings, S., and N. V. C. Polunin. 1996. Effects of fishing effort and catch rate upon the structure and biomass of fijian reef fish communities. Journal of Applied Ecology 33:400-412.

Kulbicki, M. 1998. How the acquired behaviour of commercial reef fishes may influence the results obtained from visual censuses. Journal of Experimental Marine Biology and Ecology 222:11-30.

Kulbicki, M., N. Cornuet, L. Vigliola, L. Wantiez, G. Moutham, and P. Chabanet. 2010. Counting coral reef fishes: Interaction between fish life-history traits and transect design. Journal of Experimental Marine Biology and Ecology 387:15-23.

Lima, S. L. 1998. Advances in the Study of Behavior: Stress and Behavior. Academic Press.

Lima, S. L., and L. M. Dill. 1990. Behavioral decisions made under the risk of predation: a review and prospectus. Canadian Journal of Zoology 68:619-640.

Lindfield, S. J., E. S. Harvey, J. L. McIlwain, and A. R. Halford. 2014. Silent fish surveys: bubble-free diving highlights inaccuracies associated with SCUBA-based surveys in heavily fished areas. Methods in Ecology and Evolution 5:1061-1069.

Madin, E. M. P., S. D. Gaines, J. S. Madin, and R. R. Warner. 2010. Fishing Indirectly Structures Macroalgal Assemblages by Altering Herbivore Behavior. The American Naturalist 176:785-801.

Myers, R. F. 1993. Guam's small-boat-based fisheries. Marine Fisheries Review 55:117-28.

Norberg, A., N. Abrego, F. G. Blanchet, F. R. Adler, B. J. Anderson, J. Anttila, M. B. Araújo, T. Dallas, D. Dunson, J. Elith, S. D. Foster, R. Fox, J. Franklin, W. Godsoe, A. Guisan, B. O’Hara, N. A. Hill, R. D. Holt, F. K. C. Hui, M. Husby, J. A. Kålås, A. Lehikoinen, M. Luoto, H. K. Mod, G. Newell, I. Renner, T. Roslin, J. Soininen, W. Thuiller, J. Vanhatalo, D. Warton, M. White, N. E. Zimmermann, D. Gravel, and O. Ovaskainen. 2019. A comprehensive evaluation of predictive performance of 33 species distribution models at species and community levels. Ecological Monographs 0:e01370.

Peer] reviewing PDF | (2019:04:37092:2:0:NEW 27 Apr 2020) 
576 R Core Team. 2014. R: A language and environment for statistical computing. R Foundation for

577

578

579

580

581

582

583

584

585

586

587

588

589

590

591

592

593

594

595

596

597

598

599

600

601

602

603

604

605

606

607

608

609

610

611

612

613

614

615 Statistical Computing, Vienna, Austria.

Raoult, V., L. Tosetto, C. Harvey, T. M. Nelson, J. Reed, A. Parikh, A. J. Chan, T. M. Smith, and J. E. Williamson. 2020. Remotely operated vehicles as alternatives to snorkellers for video-based marine research. Journal of Experimental Marine Biology and Ecology 522:151253.

Rizzari, J. R., A. J. Frisch, A. S. Hoey, and M. I. McCormick. 2014. Not worth the risk: apex predators suppress herbivory on coral reefs. Oikos 123:829-836.

Sale, P. F. 1998. Appropriate spatial scales for studies of reef-fish ecology. Australian Journal of Ecology 23:202-208.

Samia, D. S., E. Bessa, D. T. Blumstein, J. A. Nunes, E. Azzurro, L. Morroni, V. Sbragaglia, F. A. Januchowski-Hartley, and B. Geffroy. 2019. A meta-analysis of fish behavioural reaction to underwater human presence. Fish and Fisheries 20:817-829.

Schmiing, M., P. Afonso, F. Tempera, and R. S. Santos. 2013. Predictive habitat modelling of reef fishes with contrasting trophic ecologies. Marine Ecology Progress Series 474:201216.

Schramm, K. D., E. S. Harvey, J. S. Goetze, M. J. Travers, B. Warnock, and B. J. Saunders. 2020. A comparison of stereo-BRUV, diver operated and remote stereo-video transects for assessing reef fish assemblages. Journal of Experimental Marine Biology and Ecology 524:151273.

Shucksmith, R. J., and C. Kelly. 2014. Data collection and mapping - Principles, processes and application in marine spatial planning. Marine Policy 50, Part A:27-33.

Spitz, D. B., M. M. Rowland, D. A. Clark, M. J. Wisdom, J. B. Smith, C. L. Brown, and T. Levi. 2019. Behavioral changes and nutritional consequences to elk (Cervus canadensis) avoiding perceived risk from human hunters. Ecosphere 10:e02864.

Stamoulis, K. A., and J. M. S. Delevaux. 2015. Data requirements and tools to operationalize marine spatial planning in the United States. Ocean \& Coastal Management 116:214223.

Stamoulis, K. A., J. M. S. Delevaux, I. D. Williams, M. Poti, J. Lecky, B. Costa, M. S. Kendall, S. J. Pittman, M. K. Donovan, L. M. Wedding, and A. M. Friedlander. 2018. Seascape models reveal places to focus coastal fisheries management. Ecological Applications 28:910-925.

Stamoulis, K. A., and A. M. Friedlander. 2013. A seascape approach to investigating fish spillover across a marine protected area boundary in Hawai' 1 . Fisheries Research 144:214.

Stamoulis, K. A., E. S. Harvey, A. M. Friedlander, I. D. Williams, K. C. Weng, C. Wiggins, G. W. Wagner, and E. J. Conklin. 2019. Flight behavior of targeted fishes depends on variables other than fishing. Ecological Indicators 96:579-590.

Sward, D., J. Monk, and N. Barrett. 2019. A systematic review of remotely operated vehicle surveys for visually assessing fish assemblages. Frontiers in Marine Science 6:1-19. 
616 Thomas, L., S. T. Buckland, K. P. Burnham, D. R. Anderson, J. L. Laake, D. L. Borchers, and S. 617 Strindberg. 2006. Distance sampling. Page Encyclopedia of Environmetrics. John Wiley $618 \quad \&$ Sons, Ltd.

619 Titus, B. M., M. Daly, and D. A. Exton. 2015. Do Reef Fish Habituate to Diver Presence?

620 Evidence from Two Reef Sites with Contrasting Historical Levels of SCUBA Intensity in 621 the Bay Islands, Honduras. PLoS ONE 10.

622 Tsikliras, A. C., and K. Polymeros. 2014. Fish market prices drive overfishing of the 'big ones.' 623 PeerJ 2:e638.

624 Watson, D. L., and E. S. Harvey. 2007. Behaviour of temperate and sub-tropical reef fishes 625 towards a stationary SCUBA diver. Marine and Freshwater Behaviour and Physiology 40:85-103.

Wolanski, E., J. A. Martinez, and R. H. Richmond. 2009. Quantifying the impact of watershed urbanization on a coral reef: Maunalua Bay, Hawaii. Estuarine, Coastal and Shelf Science $84: 259-268$.

631

632

Ydenberg, R. C., and L. M. Dill. 1986. The economics of fleeing from predators. Advances in the Study of Behavior 16:229-249. 
Figure 1

Transect locations at each study site.

(A) Pūpūkea and (B) Hanauma Bay. The inset map of the island of O'ahu shows the map extents in black for each study site panel, which are the same scale. 


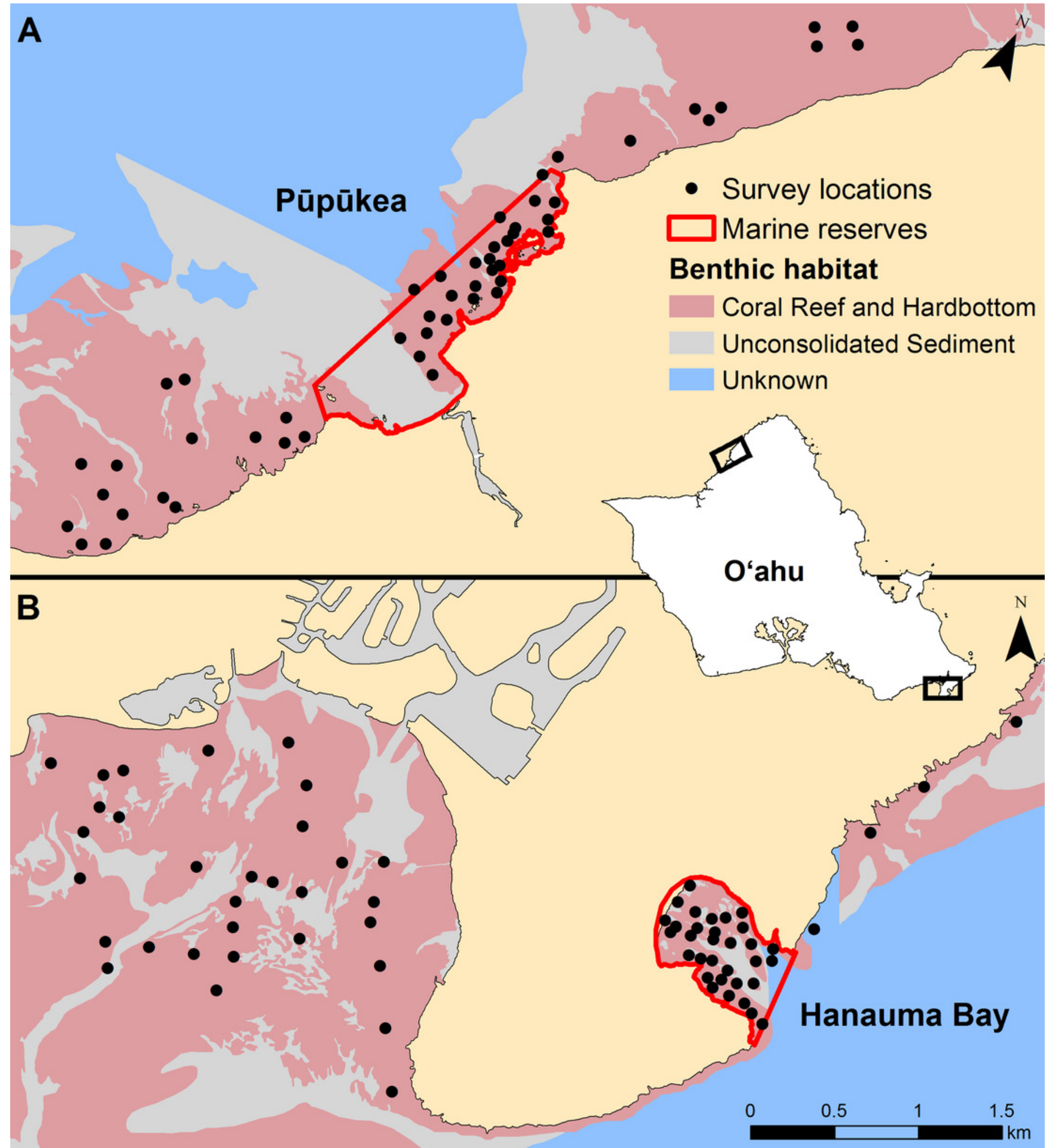




\section{Figure 2}

Diver operated stereo video (stereo-DOV) fish survey method.

Figure 2: Diver operated stereo video (stereo-DOV) fish survey method. Transect dimensions and measurement range of the stereo-DOV as the diver moves along the transect are shown. Species, number, length, and minimum approach distance (MAD) were recorded for each targeted fish species observed inside the transect dimensions and within the horizontal measurement range of the stereo-DOV. Symbols courtesy of the Integration and Application Network, University of Maryland Center for Environmental Science (ian.umces.edu/symbols/).

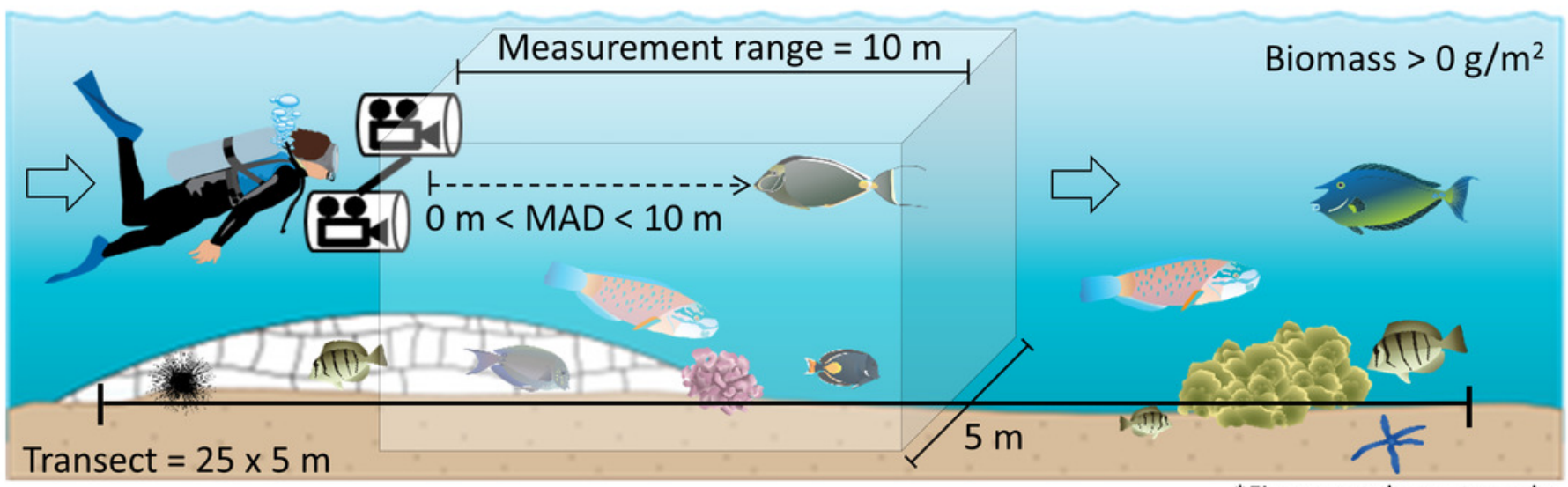

*Figure not drawn to scale 
Figure 3

Fixed effects of the generalized linear mixed model of minimum approach distance (MAD) for both sites combined.

Fixed effects and measured ranges include (A) fish length $[4-70 \mathrm{~cm}],(B)$ transect depth [0.5-17 m], (C) angle of approach [0-25 degrees], and (D) management type [OPN = fished area, RES = marine reserve $]$ by site [PUP = Pūpūkea, HAN = Hanauma Bay]. A 95-percent confidence interval is drawn around the estimated effect. All continuous variables were scaled prior to modeling and the small lines along the $x$-axis show the distribution of data for each variable.

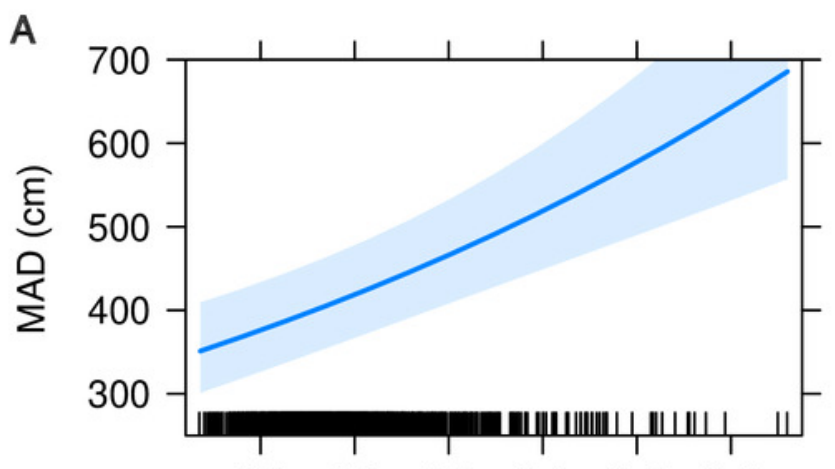

$\begin{array}{llllll}0.5 & 1.0 & 1.5 & 2.0 & 2.5 & 3.0\end{array}$

Fish Length

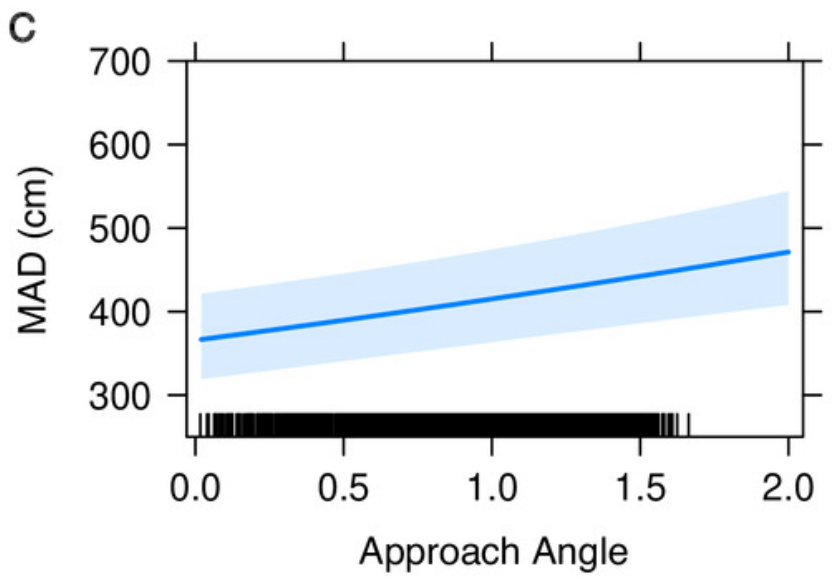

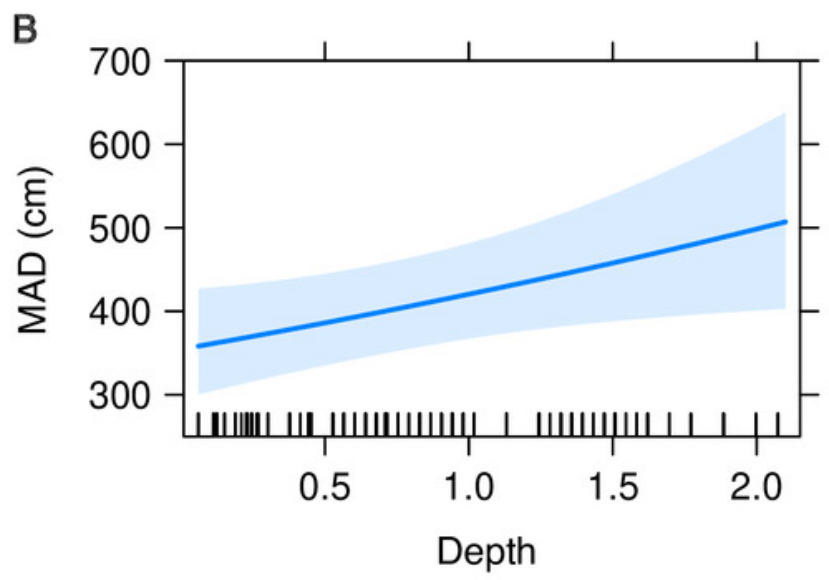

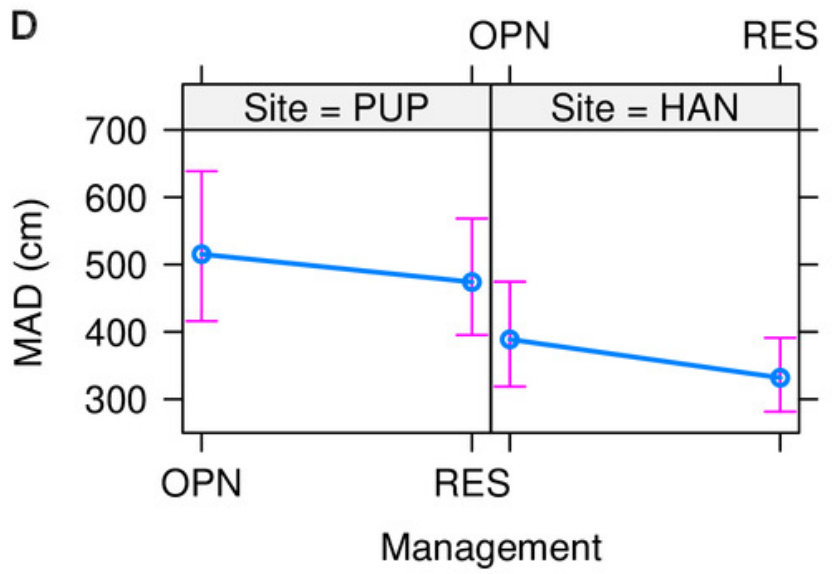




\section{Figure 4}

Partial dependence plots for boosted regression tree model of targeted fish biomass including minimum approach distance (MAD) for both sites combined.

Predictor variables and units include (A) minimum approach distance [cm], (B) longitude [decimal degrees], (C) wave power [Kw/m], (D) depth [m], (E) slope [degrees], (F) bathymetric position index - 240m radius [m], (G) turf algae percent cover [\%], and (H) bathymetric position index $-60 \mathrm{~m}$ radius $[\mathrm{m}]$. The $y$-axis represents the fitted function for targeted fish biomass. Panel labels identify predictor variables with percent variability explained in parenthesis. Small lines along $\mathrm{x}$-axis show the distribution of each predictor. 

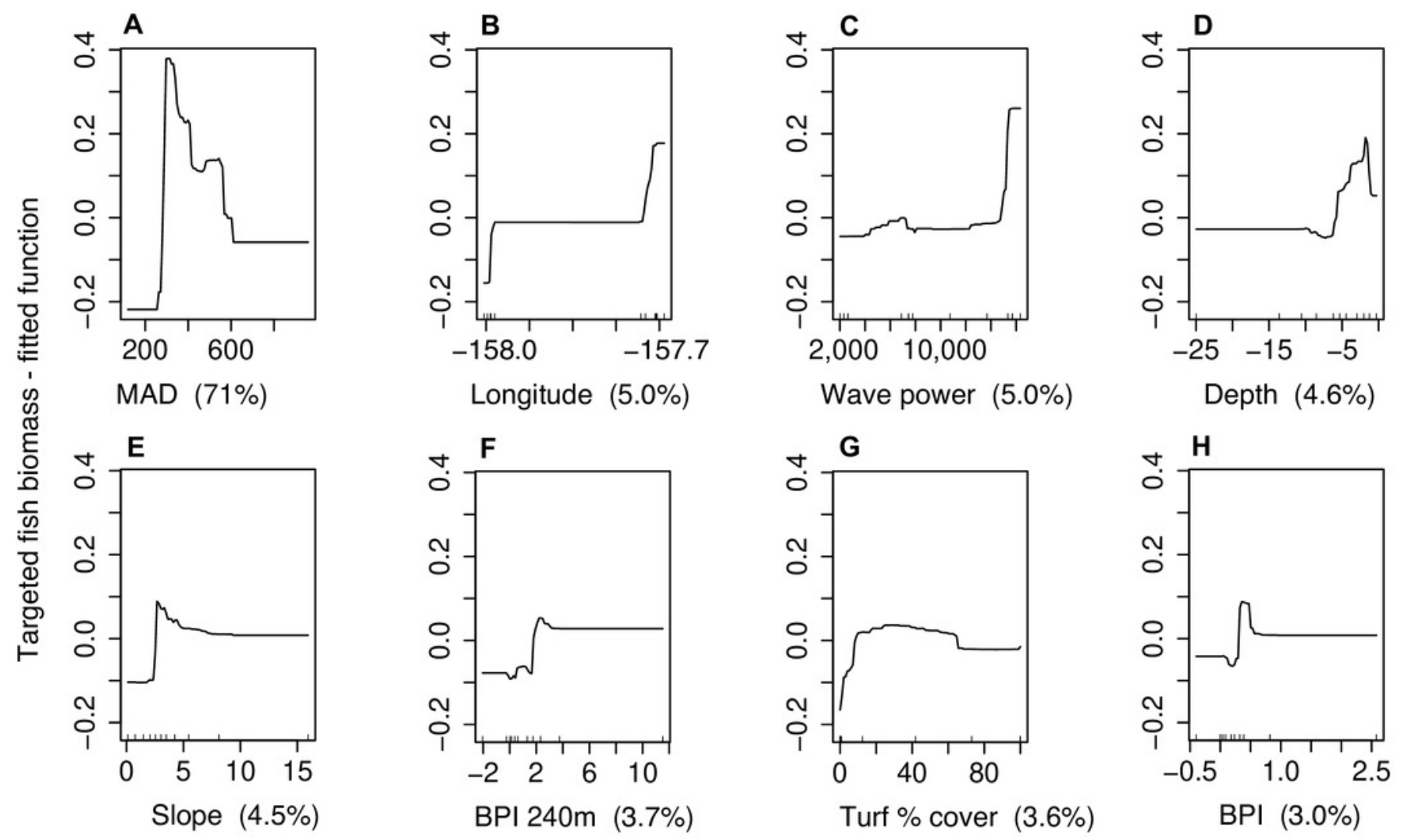


\section{Table 1 (on next page)}

Habitat predictors used in species distribution models (SDMs).

Number of individual datasets of each type indicated in parentheses. 


\section{Table 1:}

\section{Habitat predictors used in species distribution models (SDMs).}

3 Number of individual datasets of each type indicated in parentheses.

4

\section{Predictor dataset types}

Seafloor topography (12)

Benthic habitat composition (7)

Geographic (3)

Oceanographic (1)

\section{Datasets}

Depth, Slope, Slope of slope, Aspect, Planar and profile curvature, bathymetric position index

Percent cover of Crustose coralline algae, Macroalgae, Turf, and Soft bottom, Proximity index, Shannon's diversity index

Latitude, Longitude, Distance to shore

Wave Power

\section{Description}

Seafloor topography metrics derived from bathymetry including depth, slope, structural complexity, exposure, curvature, and bathymetric position index. Slope, slope of slope, and bathymetric position index were calculated at $60 \mathrm{~m}$ and $240 \mathrm{~m}$.

Percent benthic cover of major cover types, seascape fragmentation/patch isolation, habitat diversity.

Geographic location and distance from shore.

Wave height $\mathrm{x}$ wave period. 


\section{Table 2 (on next page)}

Transect and sample numbers of targeted fishes by site and management type. 
1 Table 2:

2 Transect and sample numbers of targeted fishes by site and management type.

3

\begin{tabular}{llcc} 
Site & Management & Transects & Fishes recorded \\
\hline \multirow{2}{*}{ Pūpūkea } & Reserve & 25 & 475 \\
& Open & 27 & 272 \\
\multirow{2}{*}{ Hanauma Bay } & Reserve & 35 & 572 \\
& Open & 37 & 167 \\
\hline \multicolumn{2}{r}{ Total: } & 124 & 1,486
\end{tabular}

4 


\section{Table 3 (on next page)}

Generalized linear mixed model results for minimum approach distance (MAD) combining both sites.

Fixed effects include management type, site, fish body length, transect depth, approach angle, and the interaction between management and site (Mgmt $x$ Site). Columns represent the fixed effect estimate (Estimate), standard error (Std. error), t-value, and p-value. 
1 Table 3:

2 Generalized linear mixed model results for minimum approach distance (MAD) combining

3 both sites.

4 Fixed effects include management type, site, fish body length, transect depth, approach angle,

5 and the interaction between management and site (Mgmt x Site). Columns represent the fixed

6 effect estimate (Estimate), standard error (Std. error), t-value, and p-value.

7

\begin{tabular}{l|rrrrl} 
& Estimate & Std. error & t-value & p-value & \\
\hline Management & -0.08 & 0.12 & -0.7 & 0.491 & \\
Site & -0.28 & 0.13 & -2.2 & 0.025 & $*$ \\
Fish length & 0.21 & 0.04 & 5.4 & $<0.001$ & $* * *$ \\
Depth & 0.17 & 0.08 & 2.3 & 0.024 & $*$ \\
Angle & 0.13 & 0.03 & 5.0 & $<0.001$ & $* * *$ \\
Mgmt x Site & -0.07 & 0.16 & -0.5 & 0.640 &
\end{tabular}




\section{Table 4 (on next page)}

Species distribution model (SDM) evaluation comparison for models including management (Mgmt) and management and behavior (minimum approach distance MAD).

Accuracy metrics include cross validated percent deviance explained (CV PDE), adjusted rsquared $\left(R^{2}\right)$, and gaussian rank correlation estimate (GRCE). Error metrics include crossvalidated standard error (CV SE), root mean square error (RMSE) and symmetric mean absolute percent error (SMAPE). 
1 Table 4:

2 Species distribution model (SDM) evaluation comparison for models including 3 management (Mgmt) and management and behavior (minimum approach distance -

4 MAD).

5 Accuracy metrics include cross validated percent deviance explained (CV PDE), adjusted r-

6 squared $\left(\mathrm{R}^{2}\right)$, and gaussian rank correlation estimate (GRCE). Error metrics include cross-

7 validated standard error (CV SE), root mean square error (RMSE) and symmetric mean absolute 8 percent error (SMAPE).

9

\begin{tabular}{l|cc} 
& Mgmt & MAD \\
\hline Accuracy & & \\
CV PDE & 30.5 & 68.5 \\
$\mathrm{R}^{2}$ & 0.37 & 0.74 \\
GRCE & 0.79 & 0.91 \\
Error & & \\
CV SE & 10.7 & 5.4 \\
RMSE & 32.2 & 25.2 \\
SMAPE & 1.04 & 0.91
\end{tabular}

10 